\title{
Motivations of non-Buddhists visiting Buddhist temples
}

\author{
Jaeyeon Choe $^{\mathrm{a} *}$, Michael Blazey ${ }^{\mathrm{b}}$ and Ondrej Mitas ${ }^{\mathrm{c}}$ \\ ${ }^{a}$ Recreation, Park, and Tourism Management, Pennsylvania State University, 814 Ford Building, \\ State College, PA, 16802, USA; ${ }^{b}$ California State University, Long Beach, CA, USA; ${ }^{c}$ Academy for \\ Tourism, NHTV Breda University of Applied Sciences, Breda, Netherlands
}

(Received 20 September 2012; final version received 31 December 2012)

\begin{abstract}
The current study employs the leisure motivation scale to examine motivations of nonBuddhists visiting Buddhist temples. Specifically, this investigation builds on tourism literature to explore the motivations of non-Buddhists visiting Buddhist temples in Los Angeles, California. Motivations to Buddhist temples are of particular interest given the increasing popularity in the West of Eastern spiritual activities, such as yoga and meditation, as well as the exponential growth of Buddhist-themed tourism campaigns. The findings provide insights for tourism officials responsible for promoting ways to attract tourists to Buddhist temples within their respective destinations.
\end{abstract}

Keywords: Buddhist temples; motivations; travel motivations; leisure motivation scale

\section{Introduction}

Spiritually motivated travel, 'perhaps the oldest and most prevalent type of travel in human history' (Kaelber, 2006, p. 49), has grown substantially in recent years (Timothy \& Olsen, 2006). Over the last few decades, destination marketing organisations (DMOs) worldwide have promoted tourism at sacred sites with the goal of diversifying their tourism product offerings, rejuvenating failing economies and generating funding for preservation and conservation (Russell, 1999; Vukoni'c, 1996). Such efforts have resulted in the commodification of 'sacredscapes' for an estimated 240 million individuals per year who travel to religious sites (Timothy \& Olsen, 2006). Examples of these commodified sacredscapes include renowned sites, such as Mecca and Jerusalem, cathedrals in Europe and Buddhist temples in Asia.

Buddhist temples are of particular interest given the growth of Buddhism-themed tourism campaigns in Asian countries. Increasing number of Americans are also visiting Buddhist temples in the USA, however, the popularity of Eastern spiritual activities, such as yoga and meditation has further fuelled Westerners' interest in Buddhism. For instance, it is increasingly popular for New Yorkers to visit the Buddhist Zen Mountain Monastery in upstate New York at weekends (New York Times, 2008). The current study examines non-Buddhists' motivations for visiting temples in Chinatown, Los Angeles. Throughout the USA, Los Angeles is known as a diverse cultural area that attracts large number of tourists, and Chinatown in L.A. is a popular attraction within the city. This study provides insights into the motivations of non-Buddhists visiting temples in the USA. 
This investigation contributes to an understanding of tourism as a social and psychological phenomenon (Cohen, 1974; Poria et al., 2006; Young, 1999) and it 'highlights conceptual issues that guide scholarly understanding of' the sacredscape visitor experience (Timothy \& Olsen, 2006, p. xiii). Motives for Buddhist temple visitation offer a unique opportunity for investigation because the tourism motivation literature has not addressed travel to religious sites, and research on travel to religious sites has developed separately from the tourism perspective. Thus, while motivations to visit religious sites have been discussed, our study contributes a psychological measurement of these motivations to the literature. Additionally, we offer practical managerial insights (Poria et al., 2006; Wight, 1996), particularly for destinations exploring ways to market Buddhist temples.

\section{Tourism motivation}

Tourism motivation has been of interest to tourism scholars for nearly four decades. Crompton and McKay (1997) defined tourism motivation as 'a dynamic process of internal psychological factors (needs and wants) that generate a state of tension or disequilibrium within individuals' (p. 427). Broad agreement in the tourism literature on a psychological approach to motivation has supported a wide variety of tourism motivation research. This body of knowledge may be loosely categorised into three theoretical perspectives, discussed here in the order in which they developed: push and pull theory, seeking escape dichotomy, and optimal arousal theory. While offering somewhat different accounts of specific reasons for tourists to travel, all three perspectives build on the same psychological foundation.

Dann's $(1977,1981)$ push and pull theory is one of the oldest and still most popular accounts of tourism motivation (e.g. Correia, Valle, \& Moco, 2007; Crompton, 1979; Dann, 1977; Klenosky, 2002; Oh, Uysal, \& Weaver, 1995; Wu, Xu, \& Ekiz, 2009; Yuan $\&$ McDonald, 1990). Push and pull theory provides 'a simple and intuitive approach for explaining the motivations underlying tourist behavior' (Klenosky, 2002, p. 385). Push and pull theory divides tourism motivation into two separate components. Push factors refer to people's internal forces that drive them to travel, whereas pull factors are external forces that explain why a particular destination is chosen over other locations. Some examples of push factors are 'escape from a perceived mundane environment and evaluation of self, relaxation, prestige, regression, enhancement of kinship relationships and facilitation of social interaction' (Dann, 1981, p. 191). Pull factors, in contrast, stem from the features and attributes of the designated destination, such as sunshine, relaxed tempo, friendly natives, etc., which 'respond to and reinforce "push" factor motivation' (Dann, 1981, p. 191).

Echoing Dann's (1977) two-component tourism motivation structure, Iso-Ahola (1982) posted two basic motivational dimensions in leisure behaviour, including tourism, that involve escaping and seeking (e.g. Crompton \& McKay, 1997; Kim, Broges, \& Chon, 2006; Mannell \& Iso-Ahola, 1987; Ross \& Iso-Ahola, 1991; Snepenger, King, Marshall, \& Uysal, 2006; Wolfe \& Hsu, 2008). Escaping means 'the desire to leave the everyday environment behind oneself', and seeking indicates 'the desire to obtain psychological (intrinsic) rewards through travel in a contrasting (new or old) environment' (Iso-Ahola, 1982, p. 259). Iso-Ahola concluded that 'tourism is a dialectical process because it provides an outlet for avoiding something and for simultaneously seeking something' (p. 261).

Building on Dann (1977) and Iso-Ahola (1982), Fridgen (1991) conceptualised tourism motivation as a seeking optimal arousal. According to optimal arousal theory, people seek out a level of stimulation that is best for them as individuals (Fridgen, 1991). In other words, 
'if a person's life is too quiet, the person may seek out stimulation through activity. If too much is happening in a person's world, then the person seeks to cut off stimulation and find a quieter environment' (Fridgen, p. 57). To reach an intermediate level, 'an organism may try either to increase or decrease stimulation, depending on which would achieve the optimal level' (Beck, p. 109). Fridgen (1991) emphasised that tourism provides a good opportunity for people to fulfil their need for an optimal level of stimulation. Echoing examples from Dann (1977) and Iso-Ahola (1982), Fridgen indicated that tourists are primarily motivated by the need to get away from stress, excessive stimulation, or the mundane. In other words, when travelling, people seek the stimulation or the peace they may not have in their everyday life.

Subsequent research has distinguished between different types of motivations for different groups of tourists. Utilising Cohen's tourist taxonomy, Yiannakis and Gibson (1992) explored the motives of organised mass tourists; they questioned the search for lower stimulation characteristics typically associated with this group, resulting in a suggestion that these individuals are motivated by lower risk experiences due to lack of cultural self confidence that would permit them to venture out alone. Additionally, in their claim that mass tourists are motivated by a desire for structure, they surmised they need tranquil or stimulating environments and attitudes towards strong or familiar circumstances. Unfortunately, tourism motivation research has not been extended to the context of tourism to religious sites. Therefore, it is unclear if tourists who visit religious sites fit with established accounts of tourism motivation.

\section{Travel to sacredscapes}

Studies across disciplines address the link between tourism and religious sites. For instance, Eliade (1961) stated that individuals are drawn by the desire to be within a sacred site, while Turner (1973) noted that travellers are motivated by the fact that sacred sites are located on the periphery, away from the profane world. Turner (1984) wrote that engagement in religion-based travel facilitates a level of liminality, which Eade (1992) described as travel to attain 'emotional release ... from the world of everyday structure' (p. 129). Some of the key emergent research themes encompass geospatial issues as understood by pilgrims and tourists, the relationship between religious travel and tourism, and contemporary manifestations of pilgrimage and tourism (Bremer, 2005).

In addition to the aforementioned issues, scholars are also engaged in the debate about the distinction between pilgrims and tourists. One school of thought proposes that pilgrims are indeed vastly different from tourists. For instance, Cohen (1992) argues that tourists travel away from the centre to the pleasure periphery of their world whereas pilgrims travel to the centre of their world. The view highlights elements of escapism and hedonism that are associated with the tourist. Thus, pilgrims are seen as individuals who would be motivated to travel due to their strong spiritual/religious convictions, whereas tourists would be imbued by the prospect of experiencing pleasure, satisfying curiosity, engaging in relaxation, and partaking in education (Gupta, 1999).

Another school of thought argues that it is impossible, if not nonsensical, to distinguish between the tourist and the pilgrim precisely because the two draw on the same resources and use the same amenities (Eade, 1992). From this perspective, both tourists and pilgrims are seen as utilising the same basic touristic amenities, such as infrastructure, mode of transportation, and accommodation. Tourists and pilgrims both engage in the visitation of attractions and the purchasing of souvenirs (Gupta, 1999). They only differ, therefore, in terms of their devotional adherences and preferences. In this regard, scholars, such as Smith (1992) 
have argued for a perspective that views the two groups as existing on a continuum of sacredness and secularity.

Building on the continuum thesis, Jackson and Hudman (1995) discussed the motivations of tourists visiting an English cathedral and noted that while tourists were motivated by the architectural heritage they were emotionally moved by religious feelings on site. Likewise, Schlehe (1999) noted that pilgrims might choose to first experience the religious aspects of a sacred destination and then proceed on to hedonistic activities, e.g. sun bathing. Graham and Murray (1997) further criticised the binary opposition of tourism and pilgrimage adopted by earlier studies because of its simplistic definitions of key elements, such as religious and sacred. In fact, Graham and Murray (1997) stated that the continuum does not account for the polysemous nature of the term pilgrimage within contemporary society precisely because 'holy and pious no longer define spirituality'. In this sense, as is mentioned by Timothy and Olsen (2006) 'the search for personal consciousness and meaning far transcends the religious, and pilgrimage becomes the product of a multiplicity of motivations, attitudes and behavioral mindsets' (p. 8). Thus, the current study does not make an explicit distinction between tourists and pilgrims, but rather aims to empirically examine the multiplicity of motivations that motivate individuals to travel to sacredscapes, particularly Eastern spiritual sites that are not typically the focus of tourism research (Guo, 2006).

While scholars have discussed the influence of religious/spiritual affiliation on travel motives (Collins-Kreiner \& Kliot, 2000; Fleischer, 2000), research on tourism motivations and on travel to religious sites has, unfortunately, developed along separate lines. Seminal investigations on travel to religious sites predominantly adopt an anthropological perspective and approach travel motives by highlighting the sacred attributes inherent within a given sacredscape, rather than using the psychological perspective that has dominated tourism motivation research. Contemporary anthropological perspectives emphasise a multiplicity of motives encompassing 'soul searching, intimacy with diety ... education experiences, patriotic stirrings, a chance to admire magnificent architectural and natural wonders, or simply curiosity about different cultures and religions' (Timothy \& Olsen, 2006, p. 276). While such motivations are reminiscent of general tourism motivations discussed from a psychological perspective by Dann (1977), Iso-Ahola (1982), and Fridgen (1991), the motivations of visitors to religious sites have not been examined from this perspective.

\section{Travel to Buddhist sites}

Increasing numbers of Westerners have been visiting Buddhist temples in the past few decades. Across the Pacific, DMOs literally have opened doors to Buddhist culture through campaigns aimed at Western markets promoting Buddhist tourism in Thailand, Myanmar, and Korea (James, 2008; Los Angeles Times, 2006; Philp \& Mercer, 1999; The Myanmar Times, 2009). In fact, despite economic stagnation and political crises, the number of Western visitors participating in Buddhist-themed tours in Thailand has shown steady growth of 10-20\% annually (Chinmaneevong, 2008). Some established sites, such as Borobudur's largest Buddhist monument, located in Indonesia, have in fact become flagship tourist attractions (James, 2008). Although different in their product offerings, the above sites are similar in their cognisance of the fact that their continued success, particularly in terms of fulfilling tourists' needs, lies in understanding why tourists are motivated to travel to Buddhist sites. This is a question that has been posed by religious scholars, as well as researchers specialising in travel motivations; both groups have devised numerous taxonomies designed to explicate travel motives, yet none address motivations to visit Buddhist spiritual sites. 


\section{Leisure motivation scale}

Despite great contributions to the literature, a criticism of travel motivation research has been the absence of comparable studies and lack of replicability. Scholars have addressed this issue by adapting empirical instruments designed to assess leisure motivations for the context of tourism. One such instrument is the leisure motivation scale (LMS) developed by Beard and Ragheb (1983). The scale offers four motivations; intellectual, social, competence mastery, and stimulus avoidance. The scale can be regarded as measuring continua of high versus low needs for travel (Ryan, 2002). The intellectual dimension addresses the extent to which one is motivated to travel in order to discover novel things and learn about different cultures. The social dimension examines the extent to which one travels in search of social interactions. The competence mastery dimension considers the extent to which one partakes in tourism activities that are competitive, achievement oriented, and challenging by design (Beard \& Ragheb, 1983). Lastly, the stimulus avoidance dimension focuses on the extent to which one desires to escape or remove oneself from overly stimulating day-to-day situations.

This scale has been adopted within leisure, and in part, tourism studies; however, these explorations largely have applied the scale to typical vacationscapes, such as coastal tourism (Loundsbury \& Polik, 1990; Ryan, 2002; Ryan \& Glendon, 1998; Uzzell, 1984). As such there is a paucity of empirical research utilising the scale within sacredscapes or religious sites, particularly those of Buddhist spiritual origin which are arguably experiencing increased popularity within Western society. In light of this gap in the literature, and the lack of convergence between tourism motivation and religious travel literatures, the current study employs the LMS to examine the motivations of potential visitors to Buddhist temples.

This study focuses on motivations of non-Buddhists because it can be argued that their experiences and motivations are unmediated compared to those of adherents whose practices are contingent upon the doxa of their respective ecclesiastical institutions (York, 2002). Some might attribute motives to visit Buddhist temples by non-Buddhists as characterised solely by curiosity; however, such simplistic views have been 'questioned for several decades, and it is now acknowledged that there are many complex reasons why people' make each visitation decision (Digance \& Cusack, 2002, p. 265). Similarly, tourists increasingly visit religious sites for 'architecture, art, decorative interest, tranquillity, 'sacred space' and personal contract with the 'soul' of a place' (Gutic, Caie, \& Clegg, 2010 , p. 752), as they attempt to connect a transcendental space providing spiritual meaning in a life of ephemeral values (Gutic et al., 2010). Thus, understanding tourists' motivations may help religious sites develop new arenas and partners for attracting more visitors. Managers should recognise the emotional-spiritual motivations, regardless of 215 their religious beliefs (Gutic et al., 2010).

\section{Research site}

The Chua Ba Thien Hau Buddhist temple is located along the back street of Chinatown's main shopping and restaurant area in downtown Los Angeles. Non-Buddhists often visit the temple because Chinatown and the temple are noticeable landmarks in L.A. tourism guidebooks. Also, local non-Buddhist people visit Chinatown; they often visit and stay inside of the temple for a quiet time to contemplate, or walk around to enjoy the architecture of the building and decorations, getting away from the busy city life and appreciating some traditional and different cultural experiences. That is different from the daily Los Angeles 
downtown scenes consisting of grey buildings and palm trees by the beach. On the other hand, Chinese Buddhist adherents also attend the temple frequently, conducting rituals including lighting scents, bowing to the Buddha statues, praying, chanting, and feasting. Non-Buddhist visitors appear to enjoy seeing the Buddhists' rituals as a part of the cultural experience of the site.

\section{Methods}

This study used the Beard and Ragheb (1983) Leisure Motivations Scale in the context of Buddhist temple visitation. The goal was to determine whether linkages existed between dimensions of the scale and behavioural variables associated with visiting a Buddhist temple. The scale was chosen because it is relevant to leisure experiences, possesses a proven measure of reliability and an acceptable level of content validity (Blakely \& Dattilo, 1993; Lin, Chen, Wang, \& Cheng, 2007; Lounsbury \& Polik, 1992; Mohsin \& Ryan 2007; Murray \& Nakajima, 1999; Ryan \& Glendon, 1998; Uzzell, 1984). A survey questionnaire based on the LMS scale was designed to assess motivations to visit Buddhist temples. Sections of the questionnaire comprised Buddhist temple visit-related questions, and questions based on the LMS. In the latter section, participants were asked to indicate the extent to which each of the four motivations comprised reasons for engaging in leisure activities (questions 1-7). The questionnaire ended with a series of demographic characteristics (questions 8-11), and questions designed to exclude Buddhists.

The first section of the questionnaire requested information from respondents about their temple visits and ratings on each component of the LMS. The respondents were asked: (1) the number of times they had visited a Buddhist temple in the previous 12 months; $(2-3)$ the reason for visiting the Buddhist temple and how they evaluated their temple experience; (4) their motivations for participating in any leisure activities based on the LMS; and the (5) three most important reasons for visiting that day. Questions were designed to obtain feedback about the motivation for Buddhist temple visits and the potential attraction of Buddhist temples as tourism destinations. In the second section, the questions were designed to gather respondents' demographic information, such gender, age, education, income level, and state or country of residence. In order to ensure the understandability, reliability, and validity of this survey, a pilot test was conducted. After completing the survey, testers were asked to give the researcher any suggestions and comments for improvements to the questionnaire.

The survey questionnaire was administered to a convenience sample of 240 participants on a public sidewalk in front of the Chua Ba Thien Hau Buddhist temple in Chinatown, Los Angeles, California, between 24 April and 4 July 2007.

260 Only visitors who appeared to be 18 years of age or older and non-temple members were considered for the study. Visitors were screened for a minimum age of 18 and a non-member status with regards to the temple before surveys were distributed. Survey packets were hand delivered to each respondent and the investigators collected the completed data after approximately 10-15 minutes. Investigators remained close at hand to provide assistance as needed while the self-administered questionnaires were being completed. The number of usable surveys was 179: 61 surveys were disregarded because responses to the LMS were incomplete.

SPSS was used to calculate mean scores for each element. An Independent Samples $t$-test was conducted to investigate gender differences among visitors and visitors' likelihood of visiting a Buddhist temple. In order to determine if differences existed, one-way ANOVA procedures were conducted with a chosen level of significance at 0.05 to evaluate 
differences between age, education, and income and visitors' scores on the LMS. Additionally, a one-way ANOVA was conducted to explore relationships between visitors' desire to visit a temple and visitors' scores on the LMS. A post-hoc analysis using the Bonferroni test was utilised to clarify the nature of any significant differences. The Bonferroni test was used because there were few comparisons, 'since it is difficult to show significance when there are many comparisons' (Vaske, 2008, p. 384). Scheffe's and Tukey are preferred when the number of categories is larger and useful for conducting a larger number of comparisons (Vaske, 2008).

\section{Findings}

Respondents were equally likely to be male or female, with the plurality of participants belonging to the 21-30-year age category (35.8\%), possessing a four-year college degree $(37.3 \%)$, and earning an annual income of $\$ 105,000$ or more $(18.7 \%)$. Using Beard and Ragheb's scale (1983), respondents identified leisure motivations for visiting a Buddhist temple. Two LMS scales, intellectual and stimulus avoidance, were significantly related to likelihood of visiting. The significant subscales for the former were 'to discover new things', 'to learn about things around me', 'to expand my interests', and 'to expand my knowledge' while those for the latter were 'to relieve stress and tension' and 'mentally relax'. Therefore, the important leisure motivations for these respondents appeared to be desires to engage in leisure activities of an intellectual nature and those which had an element of stimulus avoidance. An Independent Sample $t$-test was conducted to evaluate whether there were differences between gender and visitors' scores on the stimulus avoidance component of the LMS. The test was significant, $t(167)=-2.23, p=0.03$. Male respondents $(M=3.44, \mathrm{SD}=0.85)$ on average had a lower score on the component than did females $(M=3.74, \mathrm{SD}=0.95)$.

A one-way ANOVA was conducted to evaluate whether a relationship existed between visitors' desire to visit a temple and visitors' scores on the intellectual component of the LMS. The dependent variable, likelihood of visiting, included five levels: very unlikely, unlikely, neutral, likely, and very likely. The independent variable was the intellectual component of the LMS. Table 1 represents the significant results of the one-way ANOVA, $F$ (4, $174)=4.25, p=0.00$. Since there were five levels of likelihood of visiting, a post-hoc analysis was conducted in order to determine the nature of the significance.

In the post-hoc analysis using the Bonferroni test, those who marked 'very likely' had significantly higher scores on the intellectual component of the LMS (mean $=4.13, \mathrm{SD}=$ 0.78 ) than those who marked 'very unlikely' (mean $=3.47, \mathrm{SD}=0.79$ ). All other post-hoc comparisons were not significant. Thus the finding of significance in the ANOVA of a difference between the score on the intellectual component of the LMS and likelihood of temple visitation was due, for the most part, to the significant difference between the

Table 1. ANOVA of visitors' desire to visit a temple and the scores on the intellectual component of LMS.

\begin{tabular}{lccccr}
\hline & Sum of squares & $d f$ & Mean square & $F$ & Sig. \\
\hline Between groups & 8.63 & 4 & 2.16 & 4.25 & 0.00 \\
Within groups & 88.31 & 174 & 0.51 & & \\
Total & 96.94 & 178 & & & \\
\hline
\end{tabular}


outer groups - 'very likely' versus 'very unlikely'. Based on the finding that the mean scores for those 'very likely' to visit a temple (4.13) were higher than those who indicated 'very unlikely' (3.47), visitors' desires to visit a temple appeared to be strongly related to intellectual leisure motivation.

A one-way ANOVA was conducted to determine whether there were differences between visitors' desire to visit a temple and their scores on the stimulus avoidance component of the LMS. Table 2 shows that the one-way ANOVA was significant, $F(4,173)=$ $4.14, p=0.00$. Since there were five levels of likelihood on the visitors' desire, a post-hoc analysis was conducted in order to determine the nature of the significance.

In the post-hoc analysis using the Bonferroni test, those who marked 'very likely' had significantly different stimulus avoidance scores on LMS (mean $=4.10, \mathrm{SD}=0.95)$ from those who marked 'very unlikely' (mean $=3.36, \mathrm{SD}=0.91$; see appendix). All other posthoc comparisons were not significant. Thus finding significance in the one-way ANOVA of a difference between the score on the stimulus avoidance component of the LMS and likelihood of visiting a temple was due, for the most part, to the significant difference between the outer groups - 'very likely' versus 'very unlikely'. According to the fact that mean score of 'very likely' (4.10) was higher than that of 'very unlikely' (3.36), the findings suggest that visitors' desires to visit a temple were strongly related to stimulus avoidance leisure motivation. These results may indicate that respondents who were 'very likely' to visit a temple may wish to engage in the experience as a way of avoiding stimulus, given that the atmosphere of a Buddhist temple is considered to be relaxing.

Four of the items reported as most important were assigned by Beard and Ragheb (1983) to the intellectual component of the LMS; 'to discover new things', 'to learn about things around me', 'to expand my interests' and 'to expand my knowledge'. The other most important motivation, 'to relieve stress and tension', was an element of the stimulus avoidance component of the LMS.

340 The findings did not show differences between scores on the social component and the competence mastery component of LMS, and desire to visit Buddhist temples. A one-way ANOVA was conducted to evaluate if visitors' desire to visit Buddhist temples was related to visitors' scores on the social component of the LMS. The ANOVA was not significant, $F(4,172)=0.59, p=0.67$. Also, a one-way ANOVA was conducted to evaluate if visitors' desire to visit Buddhist temples was related to visitors' scores on the competence mastery component of the LMS. The ANOVA was not significant, $F(4,172)=2.46, p=$ 0.51 .

It is possible to assume that social component and competence mastery component are not compatible with stimulus avoidance component of the LMS. Consequently, visitors to a Buddhist temple might want to visit Buddhist temples to relive the stress of a busy life. The largest percentage of respondents also described their unique experience at a Buddhist temple to be 'soothing and calming'. Therefore, social component motivations like

Table 2. ANOVA of visitors' desires to visit a temple and the scores on the stimulus avoidance component of LMS.

\begin{tabular}{lcrccr}
\hline & Sum of squares & $d f$ & Mean square & $F$ & Sig. \\
\hline Between groups & 12.476 & 4 & 3.119 & 4.050 & 0.004 \\
Within groups & 132.468 & 172 & 0.770 & & \\
Total & 144.943 & 176 & & & \\
\hline
\end{tabular}


meeting new people and making friends, and competence mastery components like achieving skills would be the opposite motivations from relieving stress and tension. This supports an understanding of why respondents wish to experience relaxation when they visit Buddhist temples.

\section{Discussion}

The findings indicated that the stimulus avoidance and intellectual components were strong motivators for visiting Buddhist temples. Significant relationships were found between these two subscales and the likelihood of visiting Buddhist temples in Chinatown, Los Angeles. The significant effect of the intellectual component can be attributed to the need for participants to partake in activities wherein visitors learn, discover Buddhist values, and become acquainted with a different culture. The thought that travel presents the prospect of attaining both education and pleasurable escape has been held by numerous scholars (Cohen, 1979; Eisenberg, 1989; Kalinowski \& Weiler, 1992; Leed, 1991; Wood, 1992). In fact, some argue that learning is intricately linked to the travel experience (Kalinowski \& Weiler, 1992). According to Timothy and Olsen (2006, p. 3), this need to learn or 'search for ... enlightenment ... leads people to travel to sacrosanct sites that have been separated ritually from the profane space of everyday life'. In light of this need, they may visit, because they have an educational interest in the site or a need to understand a particular spiritual culture 'rather than being motivated purely by pleasure seeking or spiritual growth' (Timothy \& Olsen, 2006, p. 5). This type of individual is similar to Feifer's (1986) 'post-tourist' who through a communicative rationality is motivated to travel to places that stimulate intellectual development rather than experiencing Disneyfied locations. In fact, the need to travel 'in order to satisfy the need to know both mundane reality and celestial mystery is an impulse that has constantly driven humankind' (Tomasi, 2002, p. 1).

The findings indicated that participants may wish to visit Buddhist sites, because this would give them an opportunity to learn about diverse cultures and lifestyles. Describing the type of tourist to whom this type of travel appeals, Silver (1993) stated that they are 'sophisticated and usually highly-educated people' and 'may travel in morally responsible and politically correct ways' (1993, p. 316). Likewise, Weiler and Hall (1992) found that cultural tourists were relatively young, the majority tertiary-educated, and a third were in professional occupations. These demographic descriptions resonate with our findings about participants in the current study.

The significance of the stimulus avoidance dimension is attributed to participants' need to get away from daily hustle and bustle. This component entailed the need to escape overly stimulating life situations, by seeking solitude and calm situations, avoiding social contacts, and unwinding. These reasons are particularly relevant to people who have a busy life in an urban area. Visiting the temple in Chinatown, Los Angeles is a convenient opportunity for quiet time getting away from the city noise, contemplation, and relaxing from everyday responsibilities and burdens. The participants therefore regarded temple visitation as a way of escaping that Rojek (1993) described as getting away from the monotony of daily routines; this can also be viewed as getting 'away from crowds' (Steiner \& Reisinger, 2006, p. 307). As such, these people might be interested in experiencing the 'escape' or 'off the beaten path' rather than the temple itself.

The findings also resonate with Eade's (1992, p. 129) discussion about spiritually motivated individuals who travel to gain 'emotional release ... from everyday structure'. 
temporal release of social ties. In essence, they are 'betwixt and between periods of normal, everyday life' (Holmberg, 1993, p. 23). At a glance, this might seem to conflict with the stimulus avoidance component. Participants were not seeking passive leisure activities, but rather, they wanted tranquil environments that are removed from their day-to-day obligations and daily stressors wherein they can learn and discover interesting aspects of the Buddhism and Eastern culture. Motivation for more intellectually and non-stimulating leisure in this study may reflect, in part, the type of site that the participants are considering. That is, the temples provide moderately low stimulus while inviting members to learn about the Buddhist lifestyles. They are in search of a personal consciousness and meaning; meaning which can be spiritual in nature (Godbey, 1989, p. 622). It is possible that individuals who are not motivated by stimulus avoidance were underrepresented in the setting from which participants were recruited.

Additionally, the results of this study indicated no significant relationships between sociodemographic characteristics and visitors' scores on the LMS. The results of this study identified no gender difference on the total LMS; however, there was a significant difference between males and females with respect to the stimulus avoidance component, with females recording a significantly higher score on this component than males. These findings were similar to Ryan and Keith's (1995) study in which women scored higher in comparison to men on the relaxation scores. For instance, utilising seven-point Likert scale, "men rated the item "relax mentally" at 5.82, while women scored 6.14. Female participants also scored higher on "the physical relations item and on the item "to avoid the daily hustle bustle" (Ryan \& Keith, 1995, p. 45). They found very little difference between gender and the intellectual, competency and social items. With the exception of Ryan and Keith's (1995), all other extant studies revealed that males consistently scored higher than females. For example, Blakely and Dattilo (1993) reported that the women achieved lower scores on intellectual, social, and competence mastery subscales in their research sample. Lounsbury and Polik (1992) also found that men scored higher than women on the competence mastery scale. The evident gender disparity in motivations may be attributed to leisure barriers resulting from gender roles (see Henderson, Stalnaker, \& Taylor, 1988).

\section{Limitations}

The current study assumed some limitations which suggest opportunities for future research. For instance, the use of a convenience sample restricted the generalisation to larger populations. Additionally, the investigation only accounted for non-Buddhists and did not attempt to compare their motivations to those of Buddhists. Future examinations exploring the link between tourism and Buddhism might focus on the impact of Buddhist tourism on local economies, the negative cultural impacts of tourists on Buddhist sites, and the differences in visitation patterns between Buddhists and non-Buddhists.

Temple visitors' social links to Buddhism are worthy of future exploration. Finally, it would be valuable to compare the motivations for going to a temple in Los Angeles and those for going to temples in Asia.

\section{Conclusion}

Our findings revealed a significant relationship between visitors' likelihood of visiting a Buddhist temple and the intellectual and stimulus avoidance dimensions of the LMS. Additionally, women scored higher than men did with respect to stimulus avoidance. 
These findings reveal tourists' motivations to visit Buddhist temples and may be useful to tourism officials promoting Buddhist temples. Our findings suggest the importance of potential visitors' psychological needs, for example, 'escape' or 'off the beaten path'. In the current study, these reasons entail travel motivated by cerebrally enriching purposes, as well as the need to seek tranquil and serene environment that induce relaxation. The findings provide insight to those who market sacredscapes, providing them with information on how to allocate their advertising resources in a manner that effectively targets potential tourists. For instance, marketers can emphasise the learning about new things, tranquil, and serene aspects of visiting a Buddhist temple. Further opportunities for addressing visitors' intellectual development and relaxation include programmes, such as tea ceremonies, yoga, meditation and Zen classes and workshops in Buddhism, martial arts, and traditional games. Lee, Petrick, and Crompton (2007) pointed out that tourists are not motivated by the specific qualities of the destination, but rather by the match of a destination's major attributes to the travellers' psychological needs. They argued that attention should focus on locations which promote self-actualisation. The current study findings support their argument with the strong motivation of relaxation from everyday life burdens and social contacts, especially for people in urban areas like Los Angeles.

Destination officials must also be cautious about potential negative impacts induced by combining the sacred with tourism. For instance, Shackley (1998) discussed the changes in Buddhist festivals in the Himalayas as a result of the huge number of non-Buddhist tourists who neither comprehended nor revered the religious content of the event. The festival, thus was altered to take into account the presence of agnostics, consequently leading to decreased social cohesion, which was inherently one of the key purposes of the festival. An analysis weighing these impacts against socioeconomic benefits and cost would have to take place. In conclusion, managers must take care when promoting sacredscapes to strike a balance that maintains the integrity of the religious sites while producing desired economic impact.

\section{References}

Beard, G., \& Ragheb, G. (1983). Measuring leisure motivation. Journal of Leisure Research, 15(3), 219-228.

Blakely, T., \& Dattio, J. (1993). An exploratory study of leisure motivation patterns of adults with alcohol and drug addictions. Therapeutic Recreation Journal, 27(4), 230-238.

Bremer, S. (2005). Tourism and religion. In L. Jones (Ed.), Encyclopedia of religion. Detroit, MI: Macmillan.

Chang, T., Milne, S., Fallon, D., \& Pohlmann, C. (1996). Urban heritage tourism: The global-local nexus. Annals of Tourism Research, 23(2), 284-305.

Chinmaneevong, C. (2008). Good for the Spirit. Buddhist Channel. Retrieved September 12, 2008, from http://www.buddhistchannel.tv/index.php?id=52,7119,0,0,1,0

Cohen, E. (1974). Who is a tourist?: A conceptual clarification. Sociological Review, 22(4), 527-55.

Cohen, E. (1979). A phenomenology of tourist experience. The Journal of the British Sociological Association, 13(2), 5-29.

Collins-Kreiner, N., \& Kliot, N. (2000). Pilgrimage tourism in the holy land: The behavioral characteristics of Christian pilgrims. Geojournal, 50(1), 55-67.

Crompton, L. (1979). Motivation for pleasure vacation. Annals of Tourism Research, 6(4), 408-24.

Dann, S. (1977). Anomie, ego-enhancement and tourism. Annals of Tourism Research, 4(4), 184-89.

Digance, J., \& Cusack, C. (2002). Glastonbury: A tourist town for all seasons. In S. Dann (Ed.), The tourist as a metaphor of the social world (pp. 263-280). Wallingford, CT: CAB International.

Eade, J. (1992). Pilgrimage and tourism at Lourdes, France. Annals of Tourism Research, 19(1), $18-32$.

Eisenberg, G. (1989). Learning vacation. Princeton, NJ: Peterson's Guides. 
Eliade, M. (1961). The scared and the profane: The nature of religion. New York, NY: Harper \& Row. Feifer, M. (1986). Tourism in history: From imperial Rome to the present. New York, NY: Stein and Day.

Fleischer, A. (2000). The tourist behind the pilgrim in the holy land. Hospitality Management, 19(3), $311-326$.

Godbey, G. (1989). Implications of recreation and leisure research for professionals. In L. Jackson \& L. Burton (Eds.), Understanding leisure and recreation: Mapping the put, chorting the future (pp. 613-628). State College, PA: Venture Publishing.

Graham, B., \& Murray, M. (1997). The spiritual and the profane: The pilgrimage to Santiago de Compostela. Ecumene, 4(4), 389-409.

Guo, C. (2006). Tourism and the spiritual philosophies of the orient. In D. Timothy \& D. Olsen (Eds.), Tourism religion and spiritual journey (pp. 121-138). New York, NY: Routledge.

Gupta, V. (1999). Sustainable tourism: Learning from Indian religious traditions. International Journal of Contemporary Hospitality Management, 11(23), 91-95.

Gutic, J., Caie, E., \& Clegg, A. (2010). In search of heterotopia? Motivations of visitors to an English cathedral. International Journal of Tourism Research, 12(1), 750-760.

Henderson, K., Stalnaker, D., \& Taylor, G. (1988). The relationship between barriers to recreation and gender-role personality traits for women. Journal of Leisure Research, 20(1), 69-80.

Holmberg, B. (1993). Spiritual pilgrimages: Traditional and hyperreal motivations for travel and tourism. Visions in Leisure and Business, 12(2), 18-27.

Iso-Ahola, E. (1982). Towards a social psychology theory of tourism motivation. Annals of Tourism Research, 12(1), 256-262.

Jackson, H., \& Hudman, L. (1995). Pilgrimage tourism and English cathedrals: The role of religion in travel. The Tourist Review, 50(4), 40-48.

James, J. (2008). Borobudur, Path to Enlightenment. Wall Street Journal. Retrieved September 13, 2008, from http://online.wsj.com/article/SB122125202839429553.html

Kaelber, L. (2006). The sociology of medieval pilgrimage: Contested views and shifting boundaries. In L. Swatos \& L. Tomasi (Eds.), From medieval pilgrimage to religious tourism: The social and cultural economics of piety. Westport, CT: Praeger.

Kalinowski, M., \& Weiler, B. (1992). Review - educations travel. In B. Weiler \& M. Hall (Eds.), Special interest tourism. London: Belhaven Press.

Lee, S., Petrick, J., \& Crompton, J. (2007). The roles of quality and intermediary constructs in determining festival attendees' behavioral intention. Journal of Travel Research, 45(4), 402-412.

Leed, J. (1991). The mind of the traveler: From Gilgamesh to global tourism. New York, NY: Basic books.

Lin, J., Chen, L., Wang, E., \& Cheng, J. (2007). The relationship between extroversion and leisure motivation: Evidence from fitness center participation. Social Behavior and Personality, 35(10), 1317-1322.

Loundsbury, W., \& Franz, P. (1990). Vacation discrepancy: A leisure motivation approach. Psychological Reports, 66, 699-702.

Lounsbury, J., \& Polik, J. (1992). Leisure needs and vacation satisfaction. Leisure Sciences, 14(2), $105-119$.

Mohsin, A., \& Ryan, C. (2007). Exploring attitudes of Indian students toward holidaying in New Zealand using the leisure motivation scale. Asia Pacific Journal of Tourism Research, 12(1), $1-18$.

Murray, C., \& Nakajima, I. (1999). The leisure motivation of Japanese managers: A research note on scale development. Leisure Studies, 18(1), 57-65.

Muzaini, H. (2006). Backpacking Southeast Asia: Strategies of "looking local.". Annals of Tourism Research, 33(1), 144-161.

Pearce, L. (1996). Recent research in tourists' behaviour. Asia Pacific Journal of Tourism Research, 1(1), 7-17.

Pearce, P. (1993). Fundamentals of tourist motivations. In D. Pearce \& R. Butler (Eds.), Tourism research: critiques and challenges (pp. 113-134). London: Rutledge.

Philp, J., \& Mercer, D. (1999). Commodification of Buddhism in contemporary Burma. Annals of Tourism Research, 26(1), 21-54.

Poria, Y., Reichel, A., \& Biran, A. (2006a). Heritage site management: Motivation and expectations. Annals of Tourism Research, 33, 162-178. 
Poria, Y., Reichel, A., \& Biran, A. (2006b). Heritage site perceptions and motivations to visit. Journal of Travel Research, 44(3), 318-326.

Possamai, A. (2000). A profile of new agers: Social and spiritual aspects. Journal of Sociology, 36(3), $364-377$.

Rojek, C. (1993). Ways of escape: Modern transformations in leisure and travel. London: Macmillan Press.

Russell, P. (1999). Religious travel in the new millennium. Travel and Tourism Analyst, 5, 39-68.

Ryan, C. (2002). The tourism experience (2nd ed.). London: Continuum.

Ryan, C., \& Glendon, I. (1998). Application of leisure motivation scale to tourism. Annals of Tourism Research, 25(1), 169-184.

Ryan, C., \& Keith, D. (1995). Culture: Evaluating the communication process between interpreter and visitor. Tourism Management, 16(4), 295-303.

Schlehe, J. (1999). Tourism to holy sites. International Institute for Asian Studies Newsletter, 19:8.

Shackley, M. (1998). A golden calf in sacred space? The future of Saint Katherine's monastery, Mount Sinai Egypt. International Journal of Heritage Studies, 4(3), 123-134.

Silver, I. (1993). Marketing authenticity in third world countries. Annals of Tourism Research, 20(2), $302-318$

Smith, L. (1992). Introduction: The quest in guest. Annals of Tourism Research, 19(1), 1-17.

Steiner, J., \& Reisinger, Y. (2006). Understanding existential authenticity. Annals of Tourism Research, 33(2), 299-318.

The Myanmar Time. (2009). Myanmar, Thailand promote pilgrimage tourism. Myanmar Time. Retrieved March 8, 2009, from http://www.mmtimes.com/no460/n010.htm

Timothy, D., \& Olsen, D. (2006). Tourism, religion, and spiritual journey. New York, NY: Routledge.

Tomasi, L. (2002). Homo viator: From pilgrimage to religious tourism via the journey. In H. Swatos \& L. Tomasi (Eds.), Medieval pilgrimage to religious tourism. Westport, CT: Praeger.

Turner, V. (1973). The center out there: Pilgrim's goal. History of Religion, 12(3), 191-230.

Turner, V. (1984). Limiality and the performance genres. In J. MacAloon (Ed.), Rite, Drama, festival, spectacle: Rehearsals toward a theory of cultural performance (pp. 19-41). Philadelphia, PA: Institute for the Study of Human Issues.

Uzzell, D. (1984). An alternative structuralist approach to the psychology of tourism marketing. Annals of Tourism Research, 11(1), 79-99.

Vaske, J. (2008). Survey research and analysis: Applications in parks, recreation and human dimensions. State College, PA: Venture Publishing.

Vora, S. (2008). The simple life. New York Times. Retrieved December 12, 2008, from http://travel. nytimes.com/2008/12/12/travel/escapes/12ashrams.html

Vukoni'c, B. (1996). Tourism and religion. Tarrytown, NY: Elsevier.

Weiler, B., \& Hall, M. (1992). Special interest tourism. London: Belhaven Press.

Wight, A. (1996). North American ecotourism markets: Motivations, preferences, and destinations. Journal of Travel Research, 35(1), 3-10.

Wood, K. (1992). Case study - Australians studying abroad: A private sector success story in education tourism. In B. Weiler \& M. Hall (Eds.), Special interest tourism. London: Belhaven Press.

Yiannakis, A., \& Gibson, H. (1992). Roles tourists play. Annals of Tourism Research, 19(2), 287-303.

York, M. (2002). Contemporary Pagan pilgrimages. In H. Swatos \& L. Tomasi (Eds.), From medieval pilgrimage to religious tourism. Westport, CT: Praeger. 